\title{
RESEARCH PAPER \\ A SEDIMENTOLOGIC ANALYSIS OF TERRACE SEDIMENTS FROM THE PAWMPAWM RIVER CHANNEL, GHANA
}

\author{
D. O. Appiah \\ Department of Geography and Rural Development, KNUST, Kumasi \\ doappiah.cass@knust.edu.gh /dodameappiah@yahoo.com
}

\begin{abstract}
The object of this paper is to analyse the sedimentologic characteristics of old and new terrace sediments from the Pawmpawm River channel. The morphometric characteristics of the terrace materials give credence to the hydrologic dynamics of the river as it performs its core functions of erosion, transportation and deposition with time. The terrace materials are evidenced from their petrographic composition and characteristics. Analysis of terrace materials for their effective sizes, uniformity coefficient as well as Trask sorting indices has shed mure light on the sedimentologic aspects of the river terrace materials, which have undergone varying degrees of alteration in the fluid medium. Using semi-log plots of cumulative percentage curves, the terrace stratigraphic materials showed increasing and decreasing particle sizes with depth, along the Pawmpawm river channel for subsurface (old) and surface (new) terrace materials respectively. The terrace materials from the Pawmpawm River demonstrate differential size composition due to different hydrologic processes and morphologic resistance of the lithology to erosion.
\end{abstract}

Keywords: Terrace, Materials, Sorting indices, Uniformity coefficient, Pawmpawm River

\section{INTRODUCTION}

It is a truism that Streams are effective erosive agents (Jacobson et al., 2009). They remove materials from the banks and the bed of their channels in several ways (Doerr, 1990; Carlson et al., 2006). The rock thickness of about $55 \mathrm{~m}$ of the quartzite unit outcropping along the knick zones of the Pawmpawnm River (Fig.1), requires both narrowing and steepening to enhance shear stress sufficient to maintain uniform incision relative to the upper and lower gorges (Jensen, 2006; Crosby and Whipple, 2006).

Stream erosion, whether by direct lifting, abrasion, impact or cavitations, is most effective during flood stage, when the velocity and discharge are at maximum. Rivers respond 


\section{Appiah}

to a drop in their base level by incising the topography (Loget and Driessche, 2009). Progressive rejuvenation off-shoot of renewed erosion activity has also been the causes of the development of a series of terraces and knick points within lower fringes of streams (Powell and McVay, 2004; Sinha and Parker, 1996). These potentially have the tendency of truncating the hyperbolic stream profile into step-like topographic channel at the banks of the effective river valley (Carlson et al., 2006). Faster Holocene incision rates in river channel profiles may be interpreted in terms of an increase in the rates of rock uplift (Wegmann and Pazzaglia, 2002).

This phenomenon can also be akin to the general trends of stream long profile development. This is so because of the nonhomogeneity in lithologic characteristics and multi-channel morphology coupled with the changing stream regimes (Jacobson et al., 2003). The processes of river deposition complement the processes of erosion and transportation within a stream channel, ostensibly leading to a form of a dynamic equilibrium (Seidl and Dietrich, 1992). The Pawmpawm River has experienced a number of terracing mechanisms, supporting periods of major bank-full stages and recession episodes in the recent past.

Surface or new deposits of terrace sediment have different physical characteristics than the subsurface older, buried soils upon which they were deposited (Tucker et al., 1999). The buried soil is generally darker and more uniform in colour. The sediment deposits are generally less dense, with a wider range in grain sizes. Sediment deposits often show distinct stratification or layering. In the views of Chase (1992), erosion at different portions of channel slope generates different elevation levels. The transport slope-limited eroded material and deposit alluvium, are carried based on a suitable gradient threshold assumption (Sinclair and Ball, 1996).
In support of this, Carlson et al. (2006) have maintained that it is fair to mention the idea of grade as embodied in the concept of balance between erosion and deposition. This is because some streams are evidently filling in their valleys, while others are just clearly excavating theirs. The sedimentary regime in the Pawmpawm channel network is more complex but, over periods of years, a state of quasiequilibrium is plausible (Allen, 1994).

Temporal variability in bed load transport rates and spatial variability in sediment storage have been reported with increasing frequency in recent years. This is because, the mean particle size on a streambed as well as the entire spectrum of particle sizes, affect the hydraulics of flow as well as stream load transport rates (Hoey, 1992). Studies concerned with the mechanics of particle entrainment, particle transport and deposition need to include the description and comparison of particle shapes (Hayakawa and Oguchi, 2005). Studies by Tucker and Slingerland (1996) indicate that an increase in fine sediment in the channel reduces geometric mean particle size and gravel permeability. Again, the extent of sediment deposition in interstitial spaces among gravel particles does change with distance along the channel (Young et al., 1990; Bjornn and Reiser, 1991). This is because the presence or absence of unusually large particles can greatly affect the relative proportions of the other size classes (Young et al., 1990).

Sediment discharge of a river is defined as the mass rate of transport through a given cross section, measured as mass per unit time per unit width (Carlson et al., 2006; Jacobson et al., 2009). Particle size composition of suspended sediment can also be expected to vary at individual sites in response to changes in discharge, and such variations have been widely documented (Imaizumi et al., 2009; Loget and Driessche, 2009; Hoey, 1992; Jacobson et al., 2003). These define the initial conditions for a numerical study of the interactions between large-scale foreland basin and small-scale sedi- 
ment-entraining channel processes (Robinson and Slingerland, 1998). Accordingly, accurate prediction of transport rates of the largest to smallest particles in streams is important for models in which the evolution of the surface grain size distribution determines subsequent bed load morphology and transport rates (Gaeuman, et al., 2009).

However the precise nature of the relationship between particle size composition and stream discharge exhibits considerable variation (Gaeuman et al., 2009). The transport of bed and soil materials in natural water courses and the resulting changes in the configuration of the bed are important problems to the water resources projects (Doerr, 1990).

The Pawmpawm River demonstrates perennial characteristics in terms of its discharge regimes. Like most tropical small rivers, the Pawmpawm River is significant because it exhibits morphologically appealing features along its course. For instance, the river has a near perfect hyperbolic horizontal cross profile; knick points giving rise to numerous rapids and waterfalls, massive sedimentary channel basement formation, that truncate vertical erosion at most sections of the river's channel and other 'alluviation' processes (Crosby and Whipple, 2006). The sedimentologic study of the terrace materials of the river is based on the hypothesis that surface and subsurface terrace sediment bear no semblance in terms of the textural configuration. The main objective of this paper is to ascertain, through the analysis of the terrace characteristics to either corroborate or contradict the above hypothesis.

\section{MATERIALS AND METHODS}

\section{Profile of the Study Area}

The Pawmpawm River is a small tributary of the rivers Afram-Volta network system of Ghana. It was one of the major right-bank tributaries of the Afram River. The Pawmpawm Drainage basin is located on Latitude $6^{\circ} 08^{\prime}$ and $6^{\circ} 15^{\prime} \mathrm{N}$ and Longitudes $0^{\circ} 06^{\prime}$ and $0^{\circ} 18^{\prime} \mathrm{W}$ (Fig. 1 ). It is on an elevation of between $288.8 \mathrm{~m}$ and
$91.2 \mathrm{~m}$ above mean sea level within the Yilo Krobo District, North-eastern part of Koforidua and North-western part of Somanya on an angular bearing of $050^{\circ}$ and $290^{\circ}$ respectively, in the Eastern Region of Ghana.

\section{Geology of the study area}

The study area is partly covered by the Voltaian Formation as well as the weathered Togo Series. The Togo Series is made up mainly of quartzites, schists, quartzitic sandstone, phyllites and minor sandstone (Kesse, 1985). The result of Precambrian geologic upheavals (Carlson et al., 2006) led to the formation of a vast basin. In this basin, an admixture of weathered, eroded and mass gravity-moved rocks debris and sediments from the surrounding lands, were deposited. These sediments form part of the Voltaian Formation, which covers nearly two-thirds of river basin. The Voltaian Formation consists primarily of weathered sandstone, shale, mudstones, and limestone, which forms the Abetifi and the Anyaboni soil series.

The lithologic influence of the sub-stratum on the morphometry and hence the morphology of the Pawmpawm River basin is pronounced. Direct dissections of the basin by the numerous streams (Seidl and Dietrich, 1992) are in response partly to the presence of the basal lines of weakness that may have resulted from the Nkurankan-Oterkpolu and Afram faulting. Consequently the drainage pattern of the sub-basin is dendritic, reflecting the presence of massive and resistant rock to direct head-ward erosion. Thus, the effect of bedrock determines the rates and mode of fluvial action (Wohl and Ikeda, 1998). The combined effect of the above geologic characteristics and processes therefore explains the preponderance of the quartz-rich sediment and quartzite pebbles on the terraces of the Pawmpawm River basin.

\section{Field Sampling}

Three different, sampling points along the river were identified as the upper, middle and lover courses of the river. At these sections, one- 


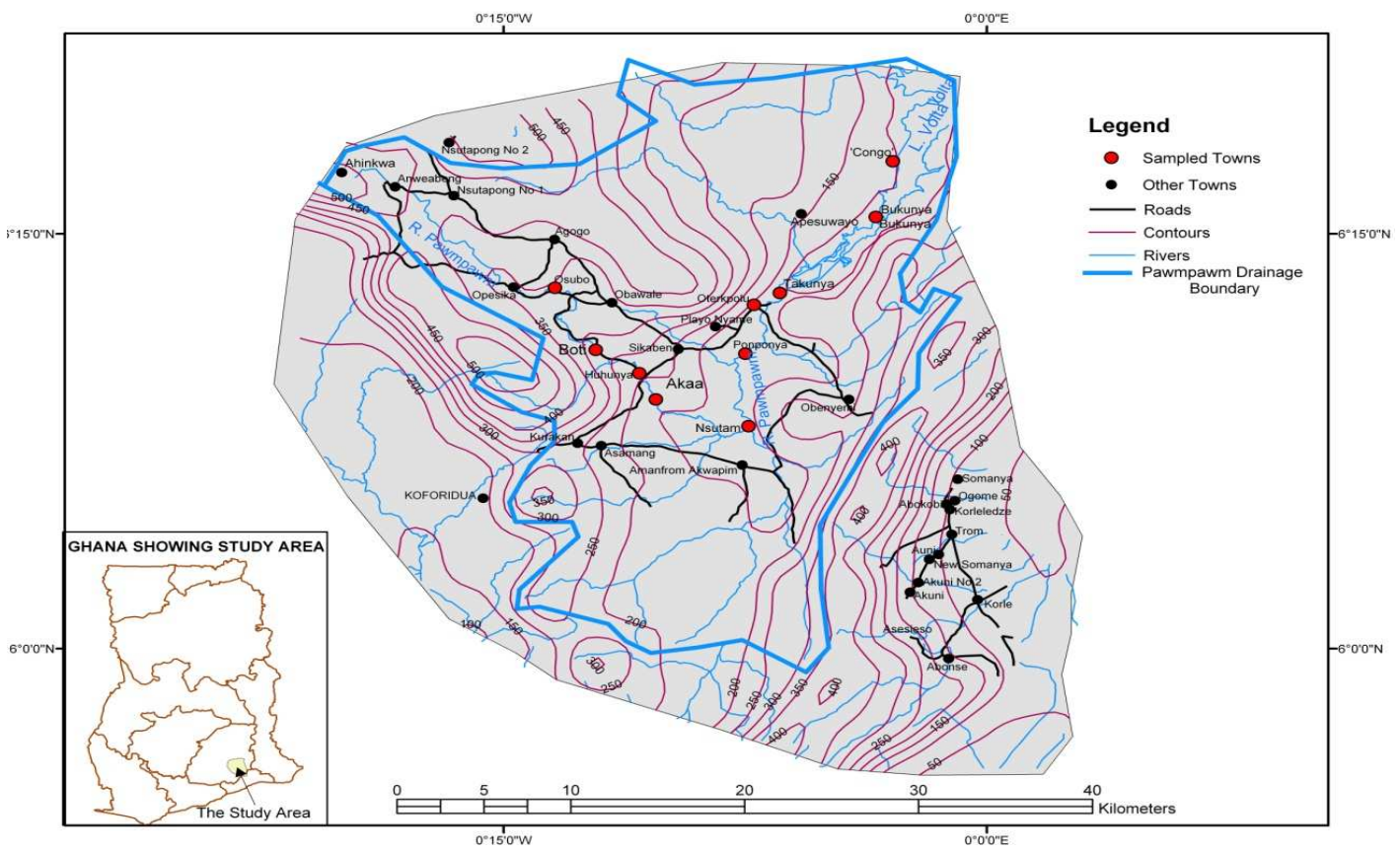

Fig. 1: Map of the Pawmpawm River Basin showing the sampling points

metre deep pits were dug at 3-metres horizontal intervals away from the effective present channel. This was to collect sub-surface (old) terrace sediments samples. Surface (new) terrace sediment samples were collected at the surface closer to the present channel bank. Some of the samples were also picked by wading through the stream; this is because wadeable streams are easier to sample when less water is in the channel (Flotemersch, et al., 2006).

\section{Terrace Sediment treatment}

Samples of variable weight for each of the subsurface and surface terrace materials were collected from the pits and some current stream channels and oven-dried at $80^{\circ} \mathrm{C}$ for about 12 hours. Fifty (50) grams each of the dried sample were weighed for treatment and analysis in the Ecological Laboratory of the University of Ghana. The samples were screened to grain fractions using sieves in the laboratory in order to determine various size distributions. Disintegrated terrace materials were subjected to mechanical analysis using U.S Standard Sieve Series, Endecotts (Filters) Ltd., London, England, sieves (See appendix 1) of the following apertures, measured in millimetres and phi values of: $(5.0,2.5,1.25$, $0.63,0.315,0.16,0.017,0.050$ and 0.40$) \mathrm{mm}$ were used.

The sieves were mounted on the mechanical shaker with the sediments and shaken for about 20-30 minutes in order to separate the particles into their respective grades of sizes passing through and those retained in the previous and the next sieve of different sieve apertures respectively. After that, the respective masses of retained sediment were determined and converted into percentages. The cumulative percentages of each type of (surface and subsurface) sediment passing through different 
sieve apertures for the samples were also recorded. Naming of the different sizes was done with reference to the Wentworth (1922) scale.

Some conversions that were made involved the extrapolation of the median, representing $50^{\text {th }}$ per cent of materials passing through sieves and percentiles $\left(\mathrm{P}_{90}\right.$ and $\left.\mathrm{P}_{10}\right)$ that represented 10 and 90 percent respectively passing through sieve from a textural semi-logarithmic chart. The size distribution of the samples were divided into size fractions based approximately on the Udden-Wentworth size classification scale and the $\varphi$-size of the particles, given by the relation $\varphi=-\log _{2} d_{m m}$, where $d_{m m}$ is the diameter of material in millimetres (Lick, 2009). A test was used to determine if differences between upstream and downstream sampling points were statistically significant at $\alpha=0.05$. This was done in order to ascertain the hypothesis that surface and sub-surface terrace sediment do not bear relational semblances and so do downstream particle sizes of sediment remain unchanged at both the upper and lower reaches of the river.

The theory underpinning the analysis of the terraces materials was based on the Geometric approach. This was used for the estimation of the various Sorting coefficients $\left(S_{o}\right)$ of the terraces sediments. This approach is commonly based on four percentiles of sediment diameters respectively: $D_{16}$ and $\mathrm{D}_{84}$ (the percentiles at the point of curvature), and D25 and D75 (the two quartiles). Trask's mixed approach uses only the three quartiles $D_{25}, D_{50}$, and $D_{75}$. On this score, Sorting coefficients $\left(S_{o}\right)$ was used to determine degree of sorting of the terrace materials. The logarithmic expression in eq. 1 was applicable in determining the sorting coefficient of the data in the following relationship:

$S_{o, \log }=\left(\frac{\log \left(D_{84}-D_{16}\right)}{2}\right)$

Alternatively, equation 1 can also be solved by a square root equation according to Simons and
Sentürk (1992) and supported by Julien and Anthony (2002) as:

$S_{o, s q r}=\sqrt{\frac{D_{84}}{D_{16}}}$

And these would yield identical results. An equation of similar form but with different percentiles was proposed by Trask in 1932. This is expressed in the form:

$S_{o, \text { Trask }}=\sqrt{\frac{D_{75}}{D_{25}}}$

The results of equations (1) and (2) with (3) are different because they are based on different percentiles. Graphic geometric sorting coefficients computed from percentiles in $\mathrm{mm}$ are dimensionless. The results also determined the qualitative descriptions defined by Folk and Ward (1957) and cited in Simon and Pye, (2001) (such as very coarse sand and moderately sorted.

\section{RESULTS AND DISCUSSION}

Textural analysis and output of terrace materials from the Pawmpawm River channel According to Young et al. (1990), particle size analysis is a common method of showing graphically the textural characteristics of a soil and sediment. This is usually done by means of particle size distribution properties such as the sorting indices, effective sizes and uniformity ratios as well as the textural properties (Young et al.,1990). In terms of graphical output, the graphs of the grain size distribution and cumulative distribution of the data were presented in both metric and phi units. Further descriptions of particle characteristics were obtained by determining the Effective size and the Uniformity coefficient from Hoffman (1994) as widely used in stratigraphic facies analysis. To throw more light on the particle characteristics of the terrace materials in the Pawmpawm river channel, textural curves were developed to show the distribution trends in the samples. 


\section{Appiah}

The computed percentage of the various grain sizes in the screened terrace sediments for surface (new) and sub-surface (old) terrace sediments alongside the respective sieve apertures are presented in Tables 1 and 2 for sampling stations at Oterkpolu, Akpan and Bukunor. The corresponding determined Sorting Indices (So), Effective Sizes (Es) and Uniformity Coefficients (Uc) for the various grain sizes are also presented in Table 3. Textural curves showing analysed terrace sediment characteri- stics and distribution trends are shown in Figs. 2 to 6.

Sub-surface terrace sediments collected up to the depth of $2 \mathrm{~m}$, and surface deposits for old and new deposits respectively, revealed perfect or near perfect sigmoid curves when graphed (Figs 2 and 5). This signifies that they are mostly moderately to well-sorted sample, with sorting coefficients $(\mathrm{So})$ in the range, $1.50 \leq \mathrm{So}$ $\leq 2.00$. The samples recorded from the Akpan

Table 1: Textural results of old terrace sediment

\begin{tabular}{cccc}
\hline Sieve apertures (mm) & Oterkpolu & $\begin{array}{c}\text { Akpan } \\
\text { Percentage passing through sieve }\end{array}$ & \multicolumn{1}{c}{ Bukunor } \\
\hline 2.5 & \multicolumn{2}{c}{ pros } & 100 \\
1.25 & 81.89 & 89 & 93.5 \\
0.63 & 76.74 & 68.2 & 93.45 \\
0.315 & 71.41 & 38.25 & 92.25 \\
0.16 & 37.41 & 10.25 & 37.25 \\
0.071 & 5.58 & 1.65 & 1.25 \\
0.05 & 2.65 & 0.65 & 0.25 \\
0.04 & 0 & 0 & 0 \\
\hline
\end{tabular}

Source: Author's fieldwork

Table 2: Textural results of new terrace sediment

\begin{tabular}{cccc}
\hline Sieve apertures $(\mathbf{m m})$ & Oterkpolu & $\begin{array}{c}\text { Akpan } \\
\text { Percentage passing }\end{array}$ & $\begin{array}{c}\text { Bukunor } \\
\text { though sieves }\end{array}$ \\
\hline 2.5 & 100.00 & 94.76 & 100.00 \\
1.25 & 99.75 & 91.14 & 90.00 \\
0.63 & 99.50 & 77.35 & 89.90 \\
0.315 & 96.50 & 29.38 & 88.90 \\
0.16 & 59.75 & 4.15 & 34.90 \\
0.071 & 8.50 & 0.33 & 1.50 \\
0.05 & 5.00 & 0.19 & 0.50 \\
0.04 & 3.00 & 0 & 0 \\
\hline
\end{tabular}

Source: Author's fieldwork 
Terrace sediments from Pawmpawm River channel ...

Table 3: Geometric characteristics of terrace sediment

\begin{tabular}{|c|c|c|c|c|c|c|}
\hline \multirow{3}{*}{$\begin{array}{l}\text { Pawmpawm } \\
\text { Sampling Points } \\
\text { Pawmpawm sampling points } \\
(\text { PSPs })\end{array}$} & \multicolumn{6}{|c|}{$\begin{array}{l}\text { Sorting indices (So Values); effective sizes and uniformity } \\
\text { coefficients }\end{array}$} \\
\hline & \multicolumn{3}{|c|}{ Sub-surface terrace sediment } & \multicolumn{3}{|c|}{ Surface terrace sediment } \\
\hline & $S_{o}$ & $\operatorname{Es}(\mathrm{mm})$ & $U c$ & $S_{o}$ & $E s(m m)$ & $U c$ \\
\hline BOTI (upper course) & $\mathrm{Nr}$ & $\mathrm{Nr}$ & $\mathrm{Nr}$ & 1.50 & 0.075 & 3.87 \\
\hline AKPAN (upper course) & 1.98 & 0.16 & 3.13 & 1.40 & 0.20 & 2.45 \\
\hline OTERKPOLU (middle course) & 2.11 & 0.08 & 3.13 & 1.50 & 0.075 & 2.27 \\
\hline $\begin{array}{l}\text { BUKUNAW (mouth and } \\
\text { flood plain) }\end{array}$ & 1.50 & 0.085 & 2.47 & 1.50 & 0.088 & 2.50 \\
\hline
\end{tabular}

Es $=$ Effective size $(\mathrm{mm})$,

Uc $=$ Uniformity coefficient

$S_{o}=$ Sorting index

$\mathrm{Nr}=$ Not recorded

subsurface terrace materials for instance, yielded a sorting Coefficient of 1.98 (Figs. 2 and 3 and Table 3 ).

Few samples were moderately sorted, from both the subsurface and surface terraces, despite occasional possible changes in the hydraulic characteristics of the transport and deposition medium, such as low flows and varying channel geometry. Some curves show well-sorted to moderately and uniformly-sorted sediments (Figs. 2 and 5), whiles others (Figs. 3 and 6) demonstrated not well graded samples, with poor sorting characteristics.

The effective size is defined as the particle size for which $10 \%$ of the soil particles are finer $\left(D_{10}\right)$. The Uniformity Coefficient is the particle size for which $60 \%$ of the soil particles are finer $\left(D_{60}\right)$. These terms though arbitrary serve as a guide in describing a soil, particularly in connection with soil consistency characteristics. The higher the Effective size, the coarser is the smallest $10 \%$ of the sample.

A higher uniformity coefficient indicates a well -graded soil sample (Hoffman, 1994; Young et al., 1990). A uniformity coefficient of unity implies that all particles are of the same size. Most terrace particles selected from the channel and the flood plain of the Pawmpawm River at various sections notably, the Boti, Akpan, Oterkpolu and the Bukunor lower (the mouth area) were very fine to coarse textured grades, as shown by the asymmetrical sigmoid curve in Fig 2.

It was also possible to calculate the So values because none of the terrace sediment sizes, both old and new, was greater than the phi value of +3 . The terrace materials showed that, the $25^{\text {th }}$ percentile of all the samples had diameters ranging from 0.071 to $0.315 \mathrm{~mm}$; that is, having radii $(r)$ in range of $(0.0355 \mathrm{~mm} \leq r \leq$ $0.1575 \mathrm{~mm})$, while the upper quartile diameters ranged from 0.16 to $0.315 \mathrm{~mm},(0.08 \mathrm{~mm} \leq r \leq$ $0.1575 \mathrm{~mm}$ ), (Figs 2 and 3 ). Thus, a positive relationship between particle size composition and stream discharge is reported.

Based on the analysis, the hypothesis that downstream particle sizes of sediment remain unchanged at both the upper and lower reaches cannot be accepted. It has been proven from the tests and laboratory analysis that sorting indices keep changing with time, though not conside- 


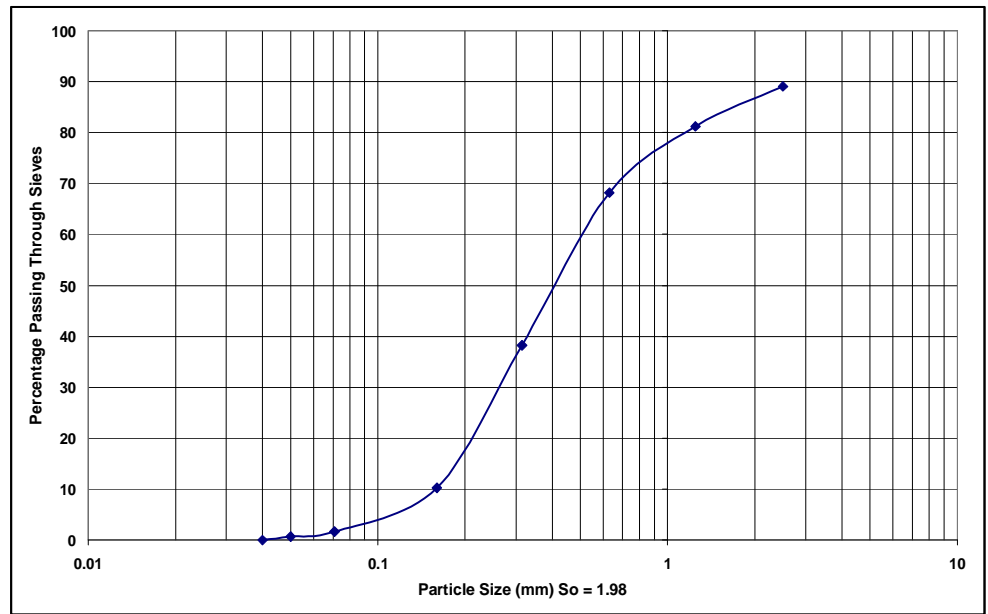

Fig. 2: Akpan sub-surface terrace particle size distribution curve

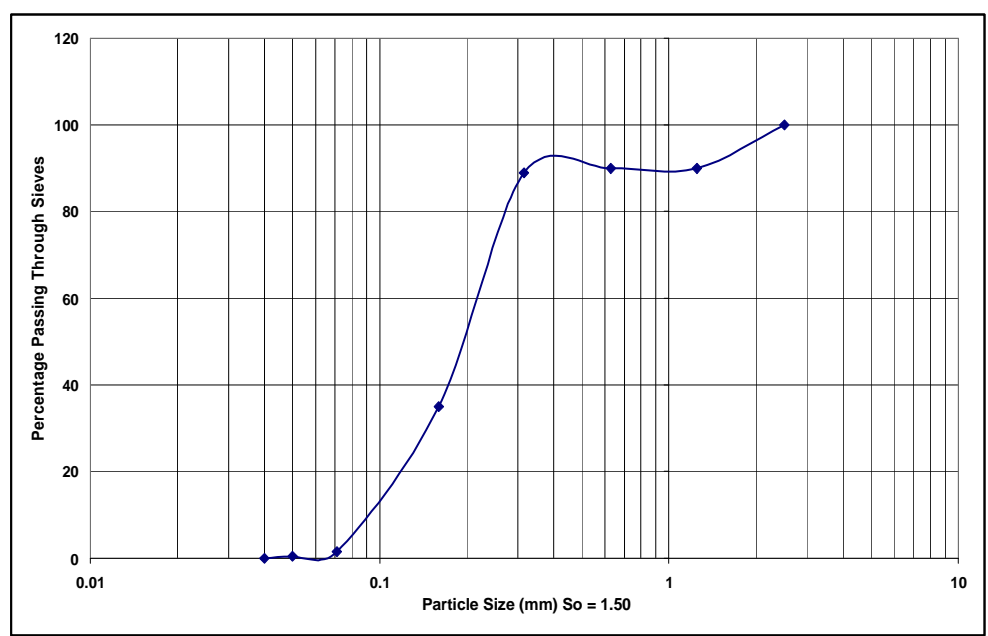

Fig. 3: Bukunor surface terrace particle size distribution curve

rably. Sequential differential deposition of materials led to particle size diminution with distance toward lower reaches. Thus, the effective sizes calculated, decreases with distance and with time, so did the sorting indices (Table 3).
The analyses of the samples implies that terrace (surface and subsurface) materials collected were of variable particle sizes configuration a function of the underlying geology (Matsuda, 2004; Grant, et al., 1990). However, almost all the samples had small values for their effective 
size $(0.075-0.2 \mathrm{~mm})$, an indication of the fact that all the samples selected have fine, finer to very fine grades. It is obvious from the analysis (Fig. 5), that terrace materials are well graded and sorted. These are further confirmed by the relatively high values of their uniformity coefficients calculated (2.27 to 3.87).

Discussions of the terrace particle characteristics

The hypothesis sought to validate or otherwise that there is no relationship whatsoever between surface (new terrace materials) and subsurface (old terrace materials), sediments from the river terrace. This is as a result of the better sequential sorting of sediment materials with the elapse of time that characterized the samples for both old and new terrace materials. There are other inherent characteristics such as the effective size and the uniformity coefficients that were used to analyse both the subsurface and surface terrace materials. These old and new terrace materials have perfect relational semblances in terms of the morphometric characteristics.

Terrace materials from the Boti plunge pool presented deposits from instant drop-down in slope along the cascade of the river into the plunged pool. The phenomenon yielded sediments of different size, mixtures from the plunge pool. Effective size of $0.075 \mathrm{~mm}$ and a uniformity coefficient of 3.87 respectively obtained for these materials indicate that about $80 \%$ of the sampled terrace materials were of uniform sizes and were poorly sorted (Fig. 4). As a result of instant deposition from the knick point, particle size configuration did not have ample time for natural sorting and grading as the materials were interspersed in armour of fine to coarse gravels deposits with particles of all sizes present (Hoffman, 1994).

The terrace materials from Oterkpolu provided information on the degree of sorting and particle morphometry in the mid-section of the river. The samples analysed yielded Effective size and uniformity coefficient of $0.08 \mathrm{~mm}$ and
3.13 respectively for subsurface terraces; while $0.075 \mathrm{~mm}$ and $2.27 \mathrm{~mm}$ effective size and uniformity coefficient were derived for the surface terrace materials respectively. Terrace sediment materials from Akpan also yielded values of $0.16 \mathrm{~mm}$ for the effective size and the uniformity coefficient of 3.13 for the subsurface terrace material, while the surface terrace materials were $0.20 \mathrm{~mm}$ effective size and a uniformity coefficient of 2.45 respectively.

Finally, the terrace materials from Bukunor (the mouth of the river) had an effective size of 0.05 $\mathrm{mm}$ and a uniformity coefficient of 2.47 , for the subsurface terrace material and $0.088 \mathrm{~mm}$ and 2.50 effective size and uniformity coefficient respectively. In addition to this, a sorting index of 1.50 was also calculated. These findings give credence to the fact that in stream terracing due to the creation of knick point in the course of the stream flow, the hydraulic capabilities to perform its effective function of erosion, transportation and deposition are intricately deciphered along the channel (Jacobson et al., 2011). These differentiation, usually, are a function of the stream energy, the morphology of the channel topography and the characteristics of the load being transported. Under these conditions, the terrace materials so deposited and sorted, would range from very well-sorted to poorly sorted as in the cases of the Akpan (Fig. 5) and the Boti (Fig. 3) plunged pool sections, respectively.

The fluvial deposits in the Pawmpawm River show a decrease in particle size toward the surface (new) from subsurface (old) stratigraphically for the channel deposits. It also shows particle size reduction from the upper through to the lower stretches of the river channel (Slattery and Burt, 1997). The reduction in particle grades 'upwards' towards the surface and 'downward' along the channel, are as a result of the reduction in the stream power. This is expressed in the differential terrace material deposition (Hayakawa and Oguchi, 2005). This is because during storm flow, the coarser mat- 


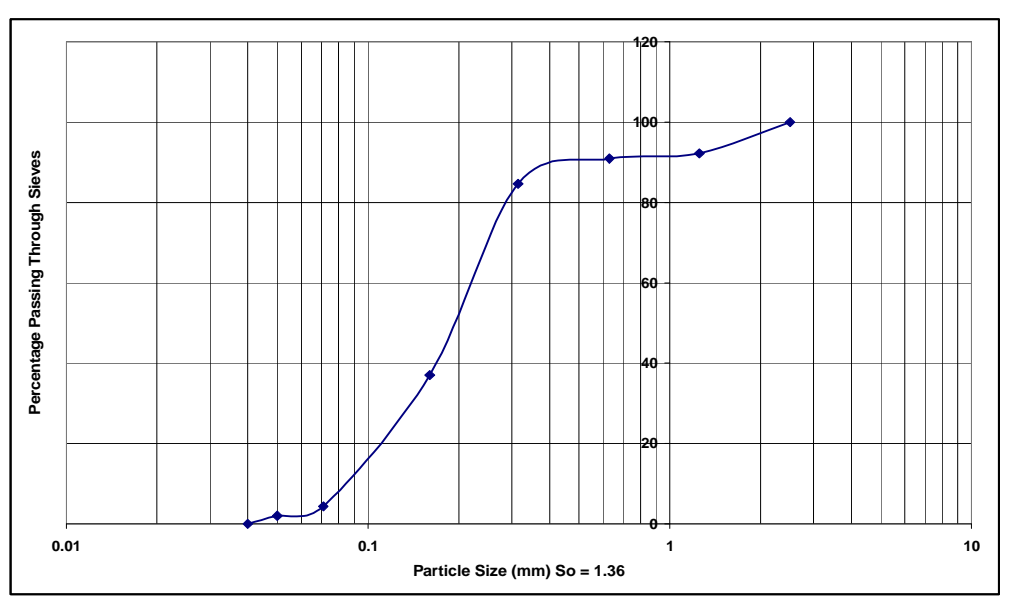

Fig. 4: Boti plunge pool terrace particle size distribution curve

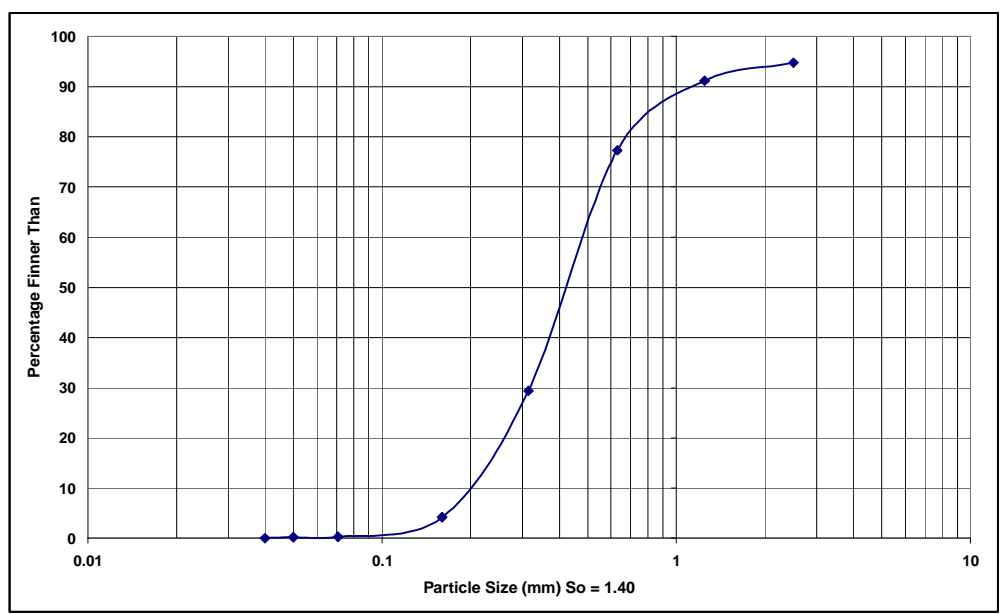

Fig. 5: Akpan surface terrace particle size distribution curve

erials are deposited in the channel beds and the finer sediments with higher phi-values are deposited at higher elevations terraces in the flood plains.

According to Matsuda (2004), reasons for the change in terrace material grain sizes with depth and distance from the channel, seems to suggest that vigorous erosive and transportation characteristics of a river do occur in some times past. Alternatively, stream storm intensity, duration, and frequency may be kept constant, in which case the processes are reduced to the "effective rainfall intensity" as the main cause (Tucker, and Slingerland, 1996), and cited in Tucker, et al., (1999).

The flow competence of palaeo-floods is 


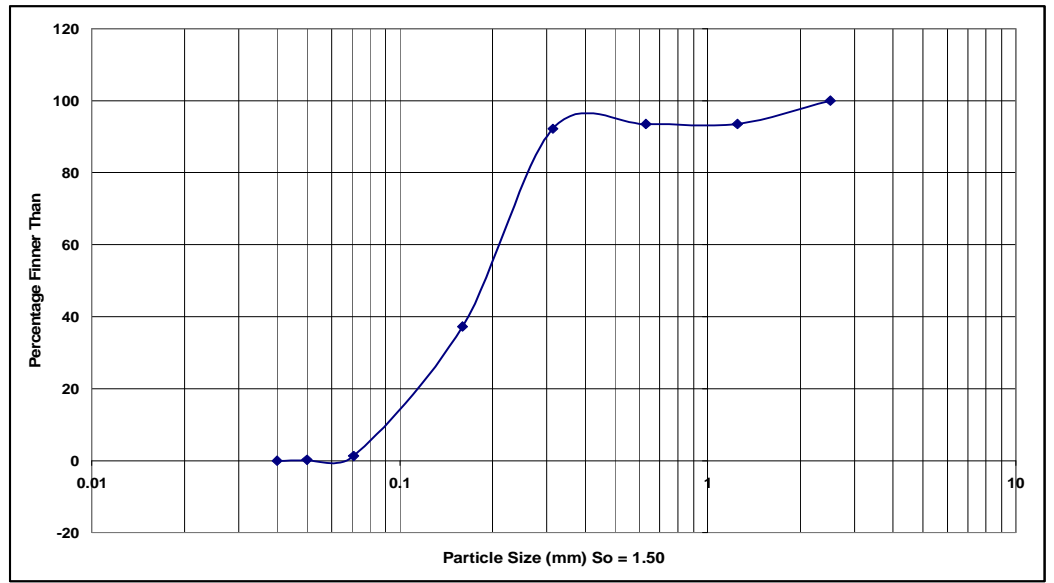

Fig. 6: Bukunor sub-surface terrace particle size distribution curve

widely inferred from their coarse-grained rivers channel deposits, which demonstrate clastic material properties (Crosby and Whipple, 2006; Wohl, 1992). Palaeo-hydrologic applications are dependent on progressive entrainment of finer to coarser particles over some measurably wide range of flow conditions (Grossman, 2001; Jacobson et al., 2011) This is a reinforcement of the assertion that the Pawmpawm River used to frequently get to its spate due to frequent over-bank flow which is also a function of high discharge supplied by intense rainfall and flush floods as evident during the field observation and measurements.

The pattern and trends of terrace materials distribution implied that there had been cases of materials re-deposition in the river channel. This is a phenomenon attributable to the fairly constant inherent hydrological dynamics of the transporting medium. This observation, therefore, agrees with observations made by Gaeuman et al. (2009), that the lower Sorting coefficients at the mouth of a river do not necessarily imply deposition under flooding condition. This condition was particularly typified at the downstream Bukunor (Fig. 6) of the Pawmpawm River, and therefore affirming the alternative hypothesis that there are considerable semblances between the surface and sub-surface terrace sediments. The plausible reason could be similar to geomorphologic and hydrologic processes that operate in tandem with reworking, re-sizing, re-sorting and redepositional activities on the petrography of the terrace sediment. This according to Gomez, (2006) could lead to the sedimentary characteristics of the terrace sediments from the upper to the lower reaches of the river, becoming altered considerably (Robinson and Slingerland, 1992).

This study supports part of the ideas of Jacobson et al (2011), that the complexities of a river system can be understood when the various sub -units are identified separately, though having an integrative dimension. The transport of sediment in natural watercourses and the resulting changes in the configuration of the bed are important (Imaizumi, et al., 2009). It must also be noted that terrace sediment is clearly important in resisting applied stress, but it is also an important control on the rate of terrace sediment settling (Jacobson et al., 2009). In a fluid under laminar flow conditions, the fall velocity or terminal velocity of a particle is reached when 
the viscous drag on the particle is equal to its submerged weight.

Thus, a positive relationship between terrace sediment composition and stream discharge is reported. But Crosby and Whipple (2006) also describe some relationship between the terrace sediment compositions that remains essentially constant over the entire range of discharge changes in the channel. The tendency for suspended sediment to become coarser as flow increases may be accounted for in terms of increasing transport capacity, and competence, which promotes collision and accretion of particles of the terrace sediment within the channel (Hayakawa and Oguchi, 2005), whereas the reverse is usually explained in terms of increased supply of fine sediment eroded from the slopes of the drainage channel (Crosby and Whipple, 2006).

\section{CONCLUSION}

Active stream competence is a measure of the energy that drives its core functions of erosion, transportation and deposition. In doing this with time, the hydrologic characteristics of the fluid medium depends largely on the load composition of the material entrainment. The Pawmpawm River has demonstrated a variety of hydro-sedimentologic characteristics, which have been expressed by the properties of its terrace materials that were analysed. The sedimentologic characteristics of the terrace materials showed a progressive diminution from the upper course of the river to the lover and mouth in the lower plains. The series of accentuated knick points that were formed from previous depositions due to successive rejuvenation of the streams channel support the assertion that the river has been considerably consistent in performing its main functions, by combining its capacity and effectiveness.

The results from the field sampling and laboratory analysis of the terrace sediments both surface (new) and subsurface (old) from the channel revealed that the materials did not deviate from each other significantly, in terms of the
Sorting Indices, Uniformity Coefficients, and Effective Sizes. The sediments showed, in respect to locations and type, very well sorted to poorly sorted grades. The particle size/grade analyses for the terrace materials have revealed that the Pawmpawm River has been transporting its load differentially, in accordance with the velocity and topography of the channel along the reach of the river. This signifies that the river over the years has been performing the functions of occasional re-working, re-sorting and re-deposition of the sediment materials in the channel. The reason identified being that the impedance to flow and occasional abrupt slack in the velocity of flow, occasioned between the Boti and Oterkpolu reaches that allowed for some limited degree of sorting and deposition.

The study recommends that for the sustainable usage of river infrastructure works such as culverts, bridges and other installations, it is important that civil engineering takes into account the dynamics of the river sediment yield ration and the stream capacity to transport its load differentially. Further studies on the flow characteristics and sediment-yielding capacity of the Pawmpawm River are recommended for future consideration.

\section{ACKNOWLEDGEMENT}

The author is grateful to the Water Resources Commission (WRC) under whose thesis grant the research was undertaken. further, the Water Research Institute (wri) of the Council for Scientific and Industrial Research (CSIR) is also appreciated for putting their sediment laboratory and equipment at my disposal at a reduced fee. Also to be appreciated with thanks is Professor L. A Dei, of the Department of Geography and Regional Planning of the University of Cape Coast for reading through the manuscript and offering salient suggestions to improve the paper. Finally the author wish to acknowledge with gratitude the secondary sources cited. 


\section{REFERENCES}

Allen, J. R. L., (1994). A continuity-based sedimentological model for temperate-zone tidal (sic) salt marshes. Geological Society of London Journal, (151): 41-49.

Bjornn, T. C. and Reiser, D. W. (1991). Habitat Requirements of Salmonids in Streams. Pages 83-138 In Meehan, W.R. (Ed.) Influences of Forest and Rangeland Management on Salmonid Fishes and Their Habitats. Special Publication 19. American Fisheries Society. Bethesda, MD.

Carlson, D. H, Plummer, C. C. and McGeary, D. (2006). Physical Geology: Earth Revealed, $6^{\text {th }}$ Edition, McGraw Hill Co. Inc, New York. 580.

Chase, C. G. (1992). Fluvial land sculpting and the fractal dimension of topography. Fractals in Geomorphology. Geomorphology, 5 (1 $-2)$ : $39-57$

Crosby, B. T., and Whipple, K. X. (2006). Knick point initiation and distribution within fluvial networks: 236 waterfalls in the Waipaoa River, North Island, New Zealand. Geomorphology, (82): 16-38.

Doerr, A. H. (1993). Fundamentals of Physical Geography. Wm C. Brown Inc. Publishers, Australia

Flotemersch, J. E., Blocksom, K., Hutchens, J. J. and Autrey, B. C. (2006). Development of a standardized large river bio-assessment protocol (LR-BP) for macro-invertebrate assemblages. River Research and Applications, 22 (7): 775-790.

Folk, R. L. and Ward, W. C. (1957). Brazos River bar: a study in the significance of grain size parameters. Journal of Sedimentary Petrology, (27):3-26.

Gaeuman, D., Andrews, E. D., Krause, A. and Smith, W. (2009). Predicting fractional bed load transport rates: Application of the Wilcock-Crowe equations to a regulated gravel bed river, Water Resource, 45, http:// w w w a g u . o r g / p u b s / crossref/2009/2008WR007320.shtml (Accessed 16 ${ }^{\text {th }}$ March, 2010).

Gomez, B. (2006). The potential rate of bedload transport. http://www.ncbi.nlm.nih.gov/ pmc/articles/PMC1859904/. (Accessed 16 ${ }^{\text {th }}$ March, 2010).

Grant, G. E., Swanson, F. J. and Wolman, M. G. (1990). Pattern and origin of stepped-bed morphology in high-gradient streams, Western Cascades, Oregon. Geological Society of America Bulletin (102): 340-352.

Grossman, M. J. (2001). Large floods and climatic change during the Holocene on the Ara River, Central Japan. Geomorphology (39): 21-37.

Hayakawa, Y. and Oguchi, T. (2005): Evaluation of gravel sphericity and roundness based on surface-area measurement with a laser scanner. Computers and Geosciences, (31): 735-741.

Hoffman, H. J. (1994). Grain-shape indices and Isometric graphs. Journal of Sedimentary Research, 64 (4): 916-920.

Hoey, T. (1992). Temporal variations in bed load transport rates and sediment storage in gravel-bed Rivers. Progress in Physical Geography, 16 (3): 319-338.

Imaizumi, F., Gomi, T., Kobayashi, S. and Negishi, J. N. (2009). Changes in bed load transport rate associated with episodic sediment supply in a Japanese headwater channel, CATENA 77 (3and 15): 207-215.

Jacobson, R. B., Blevins D. W. and Bitner, C .J. (2009). Sediment regime constraints on river restoration--an example from the Lower Missouri River. In James L. A., Rathburn, S. 
L., Whittecar, G. R. (eds) Management and restoration of fluvial systems with broad historical changes and human impacts, Geological Society of America Special Paper 451. Geological Society of America, Denver, 22.

Jacobson, R. B., Janke, T. P. and Skold, J. J. (2011). Hydrologic and geomorphic considerations in restoration of river-floodplain connectivity in a highly altered river system, Lower Missouri River, USA, Wetlands Ecological Management, 22.

Jacobson, R. B., O'Conner, J. E. and Oguchi, T. (2003). Surficial geologic tools in fluvial geomorphology. In: Kondolf, G. M., Piegay, H., (Eds.), Tools in Fluvial Geomorphology. John Wiley and Sons, New York, 25-57.

Jensen, J. D. (2006). Flood magnitudefrequency and lithologic control on bedrock river incision in post-orogenic terrain. Geomorphology 82, 39-57 www.elsevier.com/ locate/geomorph.Http://sci.hkbu.edu.hk/ math/stokes.html (Assessed 17th August 2005)

Julien, P. Y. and Anthony, D. J. (2002). Bed load motion and grain sorting in a meandering stream. Journal of Hydraulic Research, 40 (2):125-133.

Junner, N. R. and Bates D. A. (1941). The Accra earthquakes of $2^{\text {nd }}$ June 1939. Gold coast Geological Survey bulletin 13, Sir Arnold Hudson Publisher.

Kesse, G. O. (1985). The mineral and rock resources of Ghana, Rotterdam/Boston, Balkema, 601.

Lick, W. J. (2009). Sediment and Contaminant Transport in Surface Waters. Taylor and Francis Group, 389.

Loget, N. and Driessche, J. V. D. (2009). Wave train model for knickpoint migration. Geomorphology, 106 (3-4): 376-382.
Matsuda, I. (2004). River Morphology and Channel Processes, In Fresh Surface Water, James C. I. Dooge (Ed.), Encyclopedia of Life Support Systems (EOLSS), Developed under the Auspices of the UNESCO, Eolss Publishers, Oxford ,UK, http://www.eolss.net (Accessed 18 ${ }^{\text {th }}$ March 2010).

Powell, G. M and McVay, K. A. (2004). Terrace Maintenance, Agricultural Experiment Station and Cooperative Extension Service Kansas State University, 8. Kansas, USA

Robinson, R. A. J. and Slingerland, R. L. (1998). Origin of fluvial grain-size trends in a foreland basin; the Pocono Formation on the central Appalachian Basin. Journal of Sedimentary Research, 68 (3): 473-486.

Seidl, M. A. and Dietrich, W. E., (1992). The problem of channel erosion into bedrock. Catena Supplement: functional geomorphology. Landform Analysis and Models, (23): 101-124.

Simon, J. B. and Pyeearth, K. (2001). Gradistat: A Grain Size distribution and statistics package for the analysis of unconsolidated sediments surface processes and landforms. Earth Surface Process Landforms (26): 1237 -1248 .

Simons, D. B. and Senturk, F. (1992). Sediment transport technology' Water Resources Publications, Fort Collins, CO, 897.

Sinclair, K. and Ball, R. C. (1996). Mechanism for global optimization of river networks for local erosion rules. Physical Review Letters, (76): 3360-3363.

Sinha, S. K. and Parker, G. (1996). Causes of concavity in longitudinal profiles of rivers: Water Resources Research, (32):1417-1428.

Slattery, M. C., Burt, T. P. (1997). Particle size characteristics of suspended sediment in hillslope runoff and stream flow. Earth Surface 
Processes and Landforms, 22 (8):705-719.

Trask, A. (1932). Origin and environment of source sediment of petroleum. Houston., Texas.

Tucker, G. E. and Slingerland, R. L. (1996). Predicting sediment flux from fold and thrust belts. Basin Research, (8): 329-349.

Tucker, G. E., Lancaster, S. T., Gasparini, N. M. and Bras, R. L. (1999). The ChannelHillslope Integrated Landscape Development Model (CHILD) Department of Civil and Environmental Engineering, Massachusetts Institute of Technology, Cambridge, MA USA, 32

Wohl, E. E. and Ikeda, H. (1998). Patterns of Bedrock Channel Erosion on the Boso Peninsula, Japan. The Journal of Geology, 106 (3):
$331-345$

Wohl, E. E. (1992). Bedrock benches and boulder bars: Floods in the Burdekin Gorge, Australian Geological Society Annual Bulletin, 104: 770-778.

Wegmann, K. W. and Pazzaglia, F. J. (2002). Holocene strath terraces, climate change, and active tectonics: The Clearwater River basin, Olympic Peninsula, Washington State. Geological Society of America Bulletin, 114(6): 731-744.

Wentworth, C. K. (1922). A scale of grade and class terms for clastic sediments. Journal of Geology, (30): 377-392.

Young, M. K., Hubert, W. A. and Wesche, T. A. (1990). Fines in redds of large salmonids. Transactions of the American Fisheries Society (Journal Seek) (119):156-162.

\section{Appendix 1: A series of testing sieves used in the terrace materials size-sorting analysis}

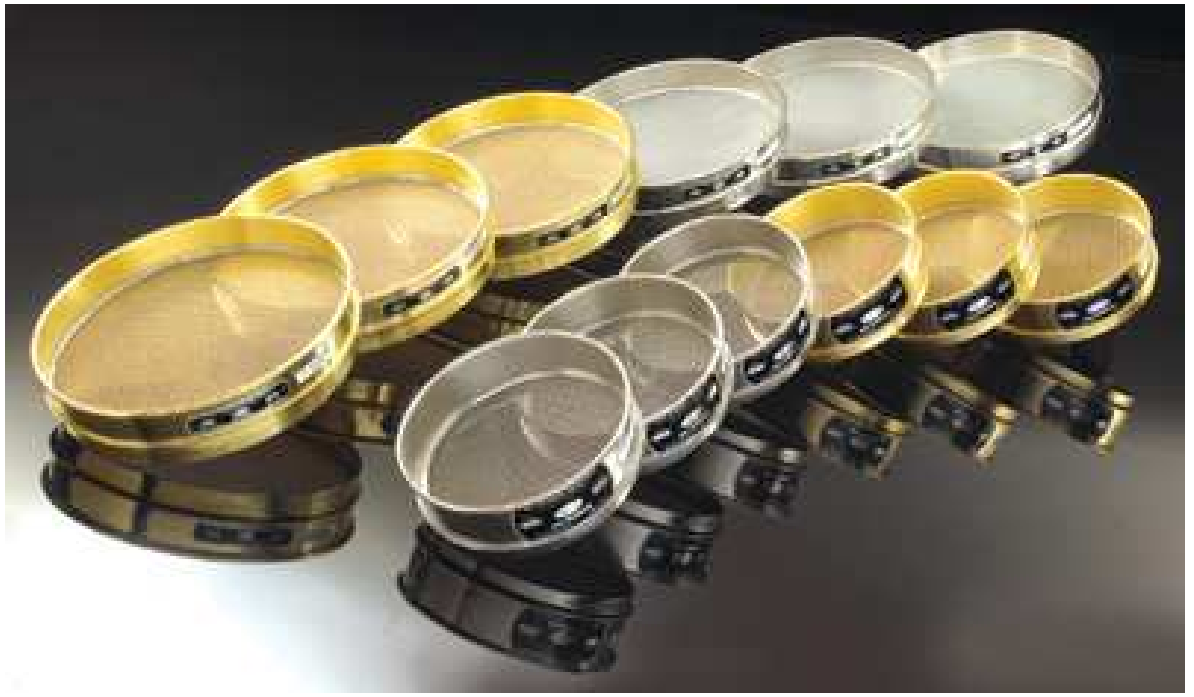

Journal of Science and Technology 다N KNST August 2014 